GSA Data Repository 2017309

\title{
Oceanic Detachment Faults Generate Compression in Extension
}

R. Parnell-Turner ${ }^{1}$, R. A. Sohn ${ }^{1}$, C. Peirce $^{2}$, T. J. Reston ${ }^{3}$, C. J. MacLeod ${ }^{4}$, R. C. Searle $^{2}$ and N. M. Simão ${ }^{2}$.

${ }^{1}$ Department of Geology \& Geophysics, Woods Hole Oceanographic Institution, Woods Hole Road, Woods Hole, MA 02543, USA

${ }^{2}$ Department of Earth Sciences, Durham University, South Road, Durham, DH1 3LE, $U K$

${ }^{3}$ School of Geography, Earth and Environmental Sciences, University of Birmingham, Birmingham B152TT, UK

${ }^{4}$ School of Earth, Ocean and Planetary Sciences, Cardiff University, Main Building, Park Place, Cardiff, CF10 3YE, UK

\section{OVERVIEW}

This supplementary document contains additional information and figures describing the processing and analyses of the microearthquake data. Further details of the elastic-plastic model for bending of the detachment footwall are also provided.

\section{DATA ACQUISITION AND PROCESSING}

\section{Arrival Detection and Hypocenter Inversion}

A network of 25 , four-component, short period OBSs was deployed between April $12^{\text {th }}$ and October $26^{\text {th }}$ 2014. OBSs were free-fall deployed approximately $2-3 \mathrm{~km}$ apart, and 23 instruments successfully recorded data. Initial $P$ - and $S$-wave arrivals were detected using an STA/LTA algorithm in the Antelope software package, and arrival times were refined with a kurtosis-based picking tool written in MATLAB (Figures DR3 and DR4; 
Baillard et al., 2014). A one-dimensional $P$-wave velocity model was constructed using the median velocity obtained from a grid of coincident wide-angle seismic refraction profiles, and draped beneath the seabed (Figure DR5; Simão et al., 2016). This model was used to predict travel times between stations and nodes within a $70 \times 70 \times 20 \mathrm{~km}(x-y-z)$ model domain at $250 \mathrm{~m}$ intervals. An $S$-wave velocity model was generated with a $V_{p} / V_{s}$ ratio of 1.8, obtained by minimizing root mean square (rms) arrival time residuals for $V_{p} / V_{s}$ values ranging from 1.4 to 2.4. Travel times were calculated using an Eikonal finite-difference scheme and NonLinLoc software (Podvin and Lecomte, 1991; Lomax et al., 2000). Initial earthquake locations were determined using the grid-search algorithm (Tarantola and Valette, 1982; Lomax et al., 2000) for 183,762 events detected by more than four OBSs. Station corrections were calculated using the sum of the average $P$ - and $S$-phase residuals at each station, and the cumulative delay times applied to successive grid-search iterations until minima were obtained.

\section{Double-Difference Hypocenter Relocation}

After applying station corrections, double-difference hypocenter relocation was carried out for 35,262 well-constrained events detected on more than nine OBSs with rms residual $<0.15 \mathrm{~s}$, using differential travel times for both $P$ - and $S$-phases from the catalog and the program hypoDD (Waldhauser and Ellsworth, 2000). A minimum of 30 catalog links per event pair were required to form a continuous cluster, with a solution obtained using a method of least squares. Five iterations were carried out, with the $P$-arrivals given twice the weighting of $S$-arrivals; a maximum event separation of $4 \mathrm{~km}$ and a cutoff threshold of $6 \mathrm{~km}$ were used for outliers located on the tails of the catalog data. A 9-layer $1 \mathrm{~d}$ velocity model was used, based upon the results of Simão et al. (2016), with a $V_{P} / V_{S}$ ratio of 1.8. The final solution yielded 18,313 double-difference relocated hypocenters.

\section{First-Motion Focal Mechanisms}

Best-fitting first-motion focal mechanism solutions for the subset of 18,313 relocated events were obtained using HASH software (Hardebeck and Shearer, 2002). Firstmotion polarities were obtained using the sign of the mean gradient of the waveform calculated over a $32 \mathrm{~ms}$ window after the $P$-wave arrival. Quality of focal mechanisms 
was assessed using multiple criteria, so that accepted mechanisms have RMS fault plane uncertainty $\leq 35^{\circ}$, weighted fraction of misfit polarities $<20 \%$, station distribution radio of $>0.4$, and mechanism probability $\geq 0.6$. In addition to these criteria, events with azimuthal gap $>90^{\circ}$ were also removed, leaving a total of 361 events with satisfactory focal mechanism solutions.

\section{Seismic Moment Estimates}

The seismic moment, $M_{0}$, for each event was calculated from the displacement spectra recorded on vertical channels, for spectral levels between 2 and $20 \mathrm{~Hz}$ (e.g. Hanks and Thatcher, 1972). $M_{0}$ can be written as

$$
M_{0}=\frac{4 \pi \rho R v^{3}}{B K} \Omega_{0}
$$

where $\rho$ is rock density $\left(3000 \mathrm{~kg} \mathrm{~m}^{-3}\right), R$ is range from event to station, $v$ is shear wave velocity at hypocenter (estimated using interpolated $1 \mathrm{~d}$ velocity model), $B$ is the average

radiation pattern coefficient $(\sqrt{2 / 5}), K$ is the seafloor reflection coefficient (1.66), and $\Omega_{0}$ is the long period limit of the displacement spectrum for an individual station. Seismic moments calculated for event-station pairs were averaged to estimate the moment for each event. With $M_{0}$ expressed in dyn $\mathrm{cm}$, local magnitude, $M_{L}$, was estimated from seismic moment for each event using

$$
\log _{10} M_{0}=1.5 M_{L}+16.1
$$

\section{ELASTIC-PLASTIC MODEL}

The model for elastic-plastic bending allows us to calculate synthetic profiles for the detachment footwall surface. The deflection of a bending plate is defined in terms of the bending moment, $M(x)$, which varies along the length of a bending profile, and the inplane force, $T$, which is the horizontal force applied to the end of the plate, and is constant along a profile (Figure 3). Far-field forces give rise to the in-plane force, which is applied from outside the bending region (e.g. ridge push/slab pull). The rheological parameters are expressed in terms of the depths and horizontal normal stresses, $\sigma_{x x}(z)$ at 
the top and base of the elastic core ( $z_{1}$ and $z_{2}$ respectively). Mathematical details of the model are described elsewhere (McAdoo et al., 1978). We require the deflected surface to dip at $20^{\circ}$ at the point of emergence at the seabed, and to have a maximum slope of no greater than $\sim 70^{\circ}$ adjacent to the spreading axis. The problem is simplified by assuming a constant stress profile and a constant yield stress of $52 \mathrm{MPa}$. We assume a Young's modulus and Poisson's ratio of $60 \mathrm{GPa}$ and 0.25 , respectively, and a density contrast between lithosphere and water of $3800 \mathrm{~kg} \mathrm{~m}^{-3}$. We vary the flexural rigidity of the bending plate, expressed in terms of $T_{e}$, in order to obtain a bending profile which best fits the observed seismicity and $20^{\circ}$ dip of the corrugated surface on the seabed. $T_{e}$ represents the mechanical strength of a bending plate, which can be thought of as a response function that does not correlate to any geological or geophysical boundary within the lithosphere.

\section{REFERENCES CITED}

Baillard, C., Crawford, W.C., Ballu, V., Hibert, C., and Mangeney, A., 2014, An automatic kurtosis-based P-and S-phase picker designed for local seismic networks: Bull. Seismol. Soc. Am., v. 104, no. 1, p. 394-409, doi: 10.1785/0120120347.

Hanks, T.C., and Thatcher, W., 1972, A Graphical Representation of Seismic Source Parameters: J. Geophys. Res., v. 77, no. 23, p. 4393-4405, doi: 10.1029/JB077i023p04393.

Hardebeck, J.L., and Shearer, P.M., 2002, A new method for determining first-motion focal mechanisms: Bull. Seismol. Soc. Am., v. 92, no. 6, p. 2264-2276, doi: $10.1785 / 0120010200$.

Lomax, A., Virieux, J., Volant, P., and Berge-Thierry, C., 2000, Probabilistic earthquake location in 3D and layered models, in Thurber, C.H. and Rabinowicz, N. eds., Advances in Seismic Event Location, Kluwer, Amsterdam, p. 101-134.

McAdoo, D.C., Caldwell, J.G., and Turcotte, D.L., 1978, On the elastic-perfectly plastic bending of the lithosphere under generalized loading with application to the Kuril Trench: Geophys. J. Int., v. 54, no. 1, p. 11-26, doi: 10.1111/j.1365246X.1978.tb06753.x. 
Podvin, P., and Lecomte, I., 1991, Finite difference computation of traveltimes in very contrasted velocity models: a massively parallel approach and its associated: Geophys. J. Int., v. 105, p. 271-284.

Simão, N., Peirce, C., Falder, M., Reston, T.J., Macleod, C.J., and Searle, R.C., 2016, Velocity structure of the crust at $13^{\circ} \mathrm{N}$ on the Mid-Atlantic Ridge: implications for crustal accretion and oceanic core complex formation: Abstract T33A-2997 presented at 2016 Fall Meeting, AGU, San Francisco, Calif. 12-16 Dec,.

Tarantola, A., and Valette, B., 1982, Generalized Nonlinear Inverse Problems Solved Using the Least Squares Criterion: Rev. Geophys., v. 20, no. 2, p. 219-232.

Waldhauser, F., and Ellsworth, W.L., 2000, A Double-Difference Earthquake Location Algorithm: Method and Application to the Northern Hayward Fault, California: Bull. Seismol. Soc. Am., v. 90, p. 1353-1368.

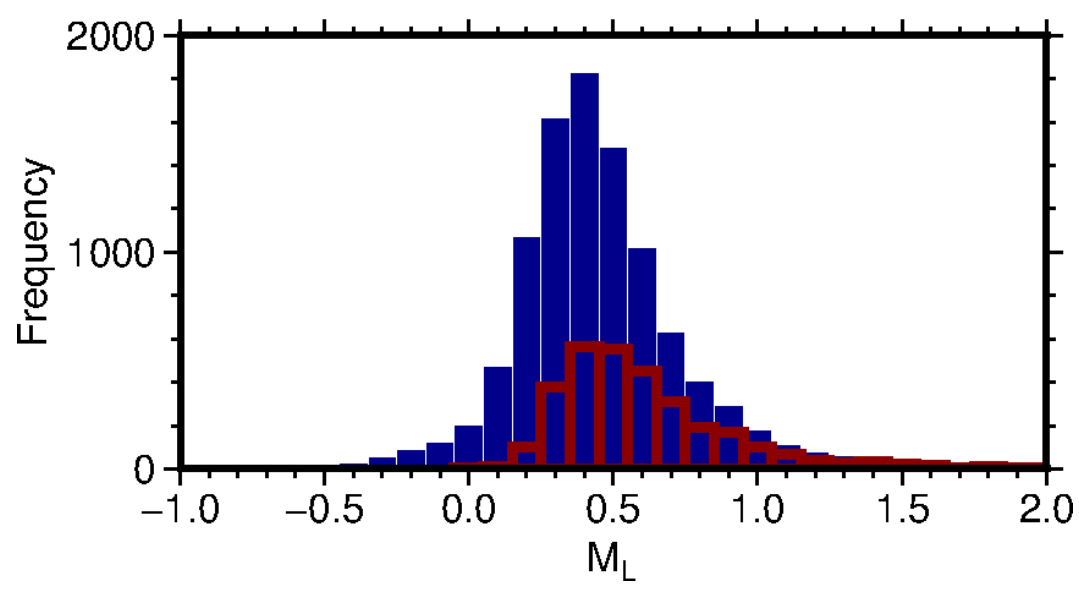

Figure DR1. Magnitude frequency histogram. Local magnitudes $\left(M_{L}\right)$ calculated for relocated events detected by $>9$ stations. Blue bars are events from domain 1; red bars are from domain 2 (see Figure 2a for locations). $M_{L}$ obtained from seismic moments, calculated using the long-period spectral level of vertical displacement spectra, and then converted into a local magnitude estimate. Cumulative moment release in domains 1 and 2 is $12.3 \times 10^{20}$ and $7.7 \times 10^{20} \mathrm{dyn}^{-1}$, respectively. 


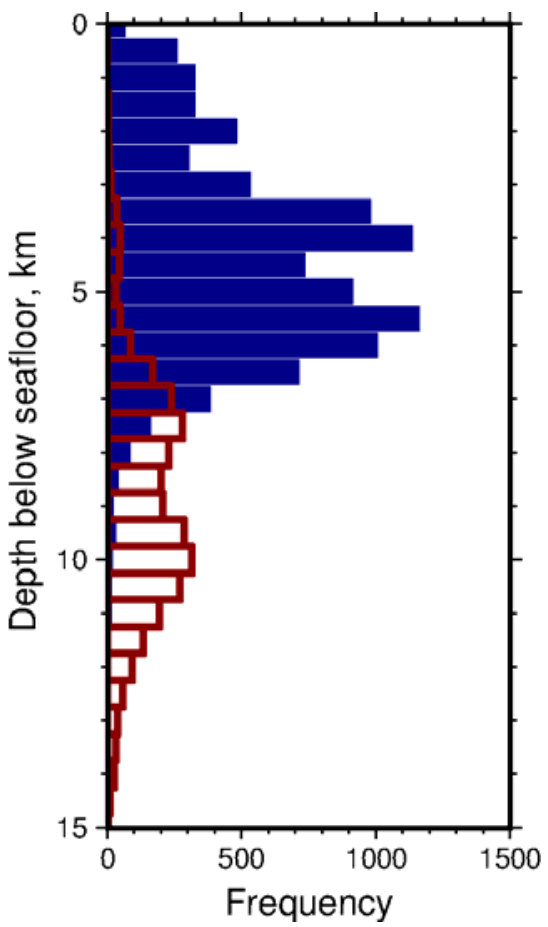

Figure DR2. Histogram of earthquake depths for domains 1 (blue) and 2 (red), see Figure $2 \mathrm{a}$ for locations. 
a

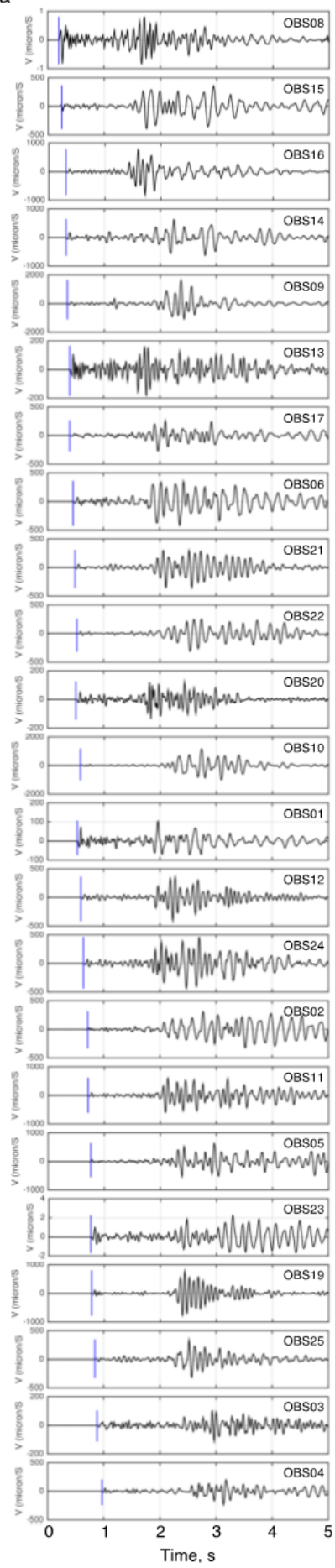

b

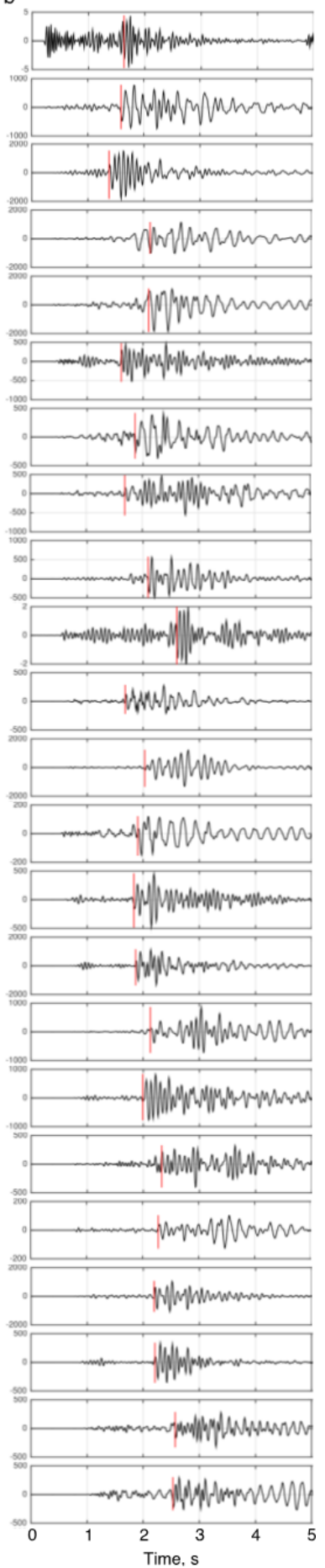

Figure DR3. Example seismograms and arrival picks for an extensional event located near the spreading axis. Event hypocenter at $13^{\circ} 21.298^{\prime} \mathrm{N}, 44^{\circ} 52.030^{\prime} \mathrm{W}$, depth below seabed $8.4 \mathrm{~km}, M_{L}=1.7$ at $05: 48$ UTC on $9^{\text {th }}$ July 2014 . a: Vertical component of velocity and compressional $(P)$ wave phase picks (blue lines). b: Horizontal component of velocity and shear $(S)$ wave phase picks (red lines). OBS numbers annotated, data band-pass filtered from $1-25 \mathrm{~Hz}$. 

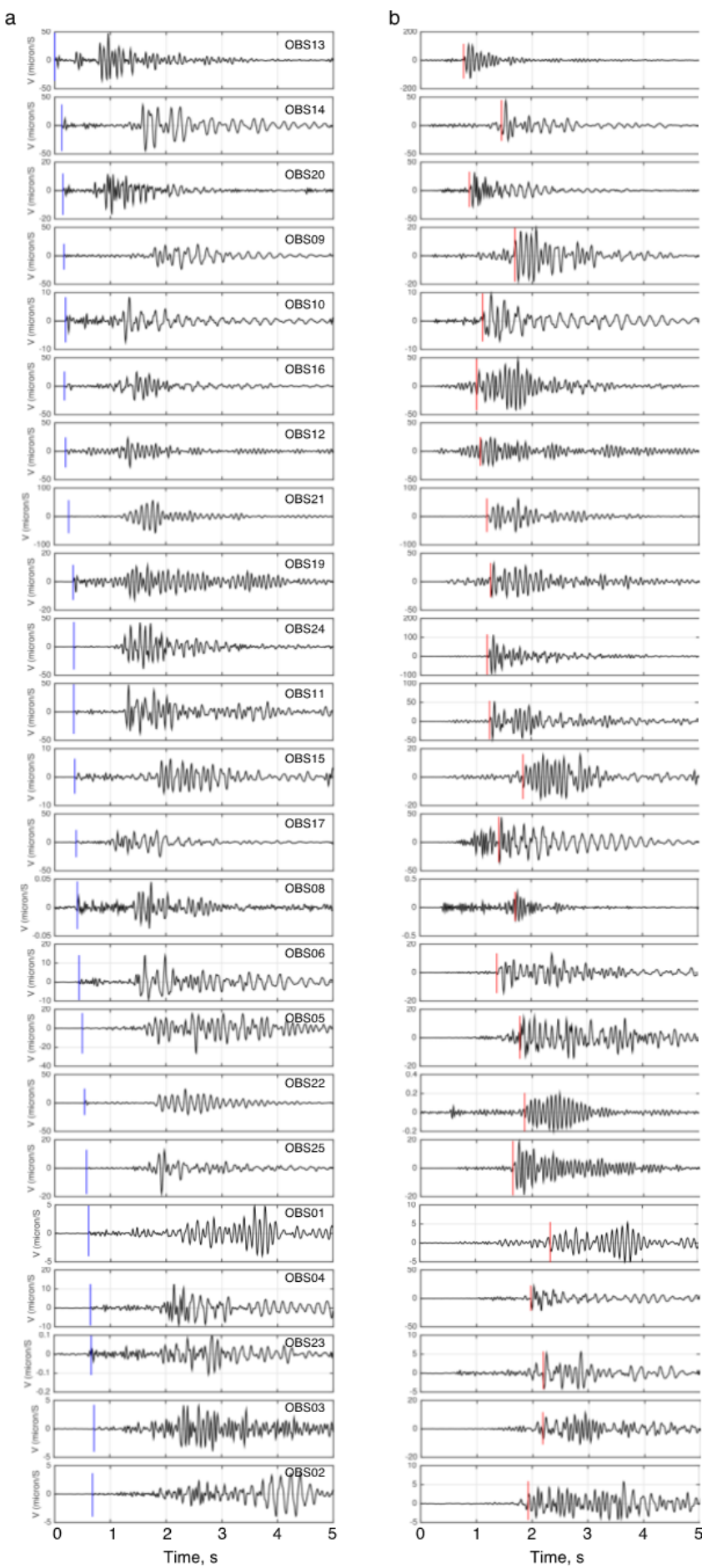

Figure DR4. Example seismograms and arrival picks for a compressional event located near the $13^{\circ} 20^{\prime} \mathrm{N}$ detachment fault. Event hypocenter at $13^{\circ} 20.740^{\prime} \mathrm{N}, 44^{\circ} 53.810^{\prime} \mathrm{W}$, depth below seabed $4.8 \mathrm{~km}, M_{L}=1.7$ at $22: 54$ UTC on $29^{\text {th }}$ June 2014 . a: Vertical component of velocity and compressional $(P)$ wave phase picks (blue lines). b: Horizontal component of velocity and shear $(S)$ wave phase picks (red lines). OBS numbers annotated, data band-pass filtered from 1-25 Hz. 


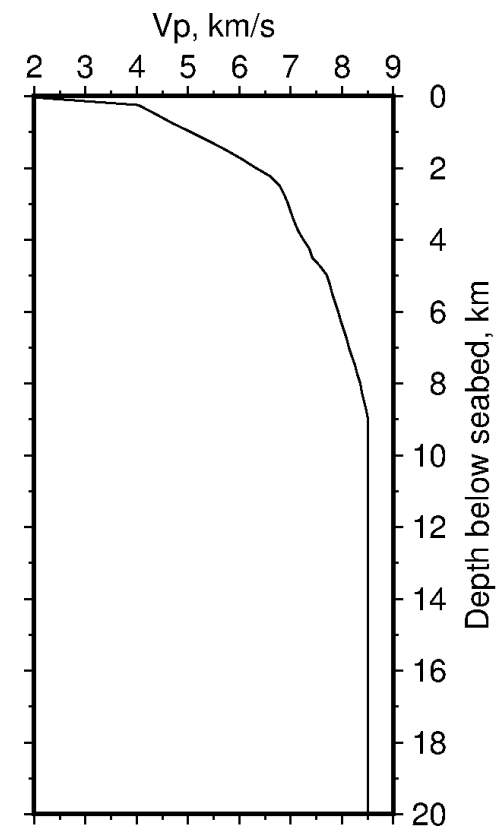

Figure DR5. $P$-wave velocity model used in the travel-time calculation. Model constructed by draping a median 1-dimensional $P$-wave model obtained from coincident wide-angle active-source seismic experiment (Simão et al., 2016). 